\title{
O IMPACTO DA PROPRIEDADE INTELECTUAL SOBRE FÁRMACOS NA EFETIVAÇÃO DO DIREITO À SAÚDE
}

\author{
Camila Baraldi*
}

RESUMO: O Acordo TRIPS sobre os direitos de propriedade intelectual relaciona-se diretamente com a efetivação do direito à saúde, em específico com o acesso das populações aos medicamentos de que necessitam. Tal acordo reflete claramente os interesses dos países desenvolvidos e as exceções nele previstas, mais que flexibilizá-lo, confirmam o seu caráter privatista. A atual situação da saúde pública nos países em via de desenvolvimento reflete a inadequação deste sistema sob o prisma dos direitos humanos.

PALAVRAS-CHAVE: TRIPS. Direito à saúde. Propriedade intelectual. Internacionalização do direito.

RÉSUMÉ: L'Accord sur les aspects des droits de propriété intellectuelle qui touchent au commerce (ADPIC) et l'effectivité du droit à la santé ont une forte liaison, surtout en ce qui concerne l'accès de la population aux médicaments qui lui sont nécessaires. Cet accord reflète clairement les intérêts des pays développés et les exceptions y prévues, plus que l'assouplir, confirment son qualité privatiste. La situation actuelle de la santé publique dans les pays en voie de développement montre l'inadéquation de ce système sous le point de vue des droits de l'homme.

MOTS-CLE : ADPIC. Droit à la santé. Propriété intellectuelle. Internationalisation du droit.

*Acadêmica do $9^{\circ}$ semestre do Curso de Direito da Universidade Federal de Santa Maria (UFSM), laureata in Scienze Giuridiche Europee e Transnazionali pela Universidade de Trento - Itália e diplomée - licence en Droit - pela Universidade de Paris XIII França. 


\section{OS LIMITES DO MARCO REGULATÓRIO INTERNACIONAL EM MATÉRIA DE MEDICAMENTO}

O acordo TRIPS obriga os países membros da OMC a adotar determinadas regras de proteção da propriedade intelectual, sobretudo a obrigatoriedade de reconhecer a patenteabilidade de produtos farmacêuticos. A apropriação do saber, quando diz respeito a bens essenciais à vida humana reveste-se de um caráter extremamente perverso, como no caso dos medicamentos (1.1). Entre as flexibilizações previstas para mitigar este desvio, encontram-se as licenças obrigatórias, pouco utilizadas, que terminam meramente por legitimar o acordo frente às pressões dos movimentos sociais (1.2).

\subsection{A privatização do saber}

O acordo TRIPS $^{1}$ - Acordo sobre aspectos dos direitos de propriedade intelectual relacionados ao comércio - faz parte do direito da Organização Mundial do Comércio (OMC). Com a sua adoção em 1994, os direitos de propriedade intelectual que antes eram tratados em instância específica, a Organização Mundial da Propriedade Intelectual (OMPI) e nos termos da Convenção de Paris assinada em 1883, foram trazidos para a OMC, organização que tem como objetivo promover o livre comércio.

Os bens imateriais, dentre as quais as criações intelectuais, são insuscetíveis de apropriação material. Deste modo, ou utiliza-se o direito para reconhecer que a propriedade destas pertença à alguém e, deste modo, impor sanções a quem não a respeite ou, neste caso, o segredo também pode ser útil ao fim de impedir que outros desfrutem do conhecimento produzido ${ }^{2}$.

A opção do TRIPS foi pelos direitos de propriedade intelectual. As patentes são apenas uma das modalidades destes direitos e aplicam-se às inovações tecnológicas e científicas. A principal justificativa para a existência destes direitos é a de que sem tal proteção e sem os benefícios econômicos que deles decorrem, a pesquisa científica seria desestimulada.

Esta afirmação, no entanto, é bastante questionável. No caso específico das indústrias farmacêuticas, não se negam os grandes investimentos necessários para o

\footnotetext{
TRIPS (Acordo sobre aspectos dos direitos de propriedade intelectual relacionados ao comércio) Disponível em : 〈http://www.wto.org/english/docs_e/legal_e/legal_e.htm\#TRIPs > . Acesso em 15 jul. 2007.

2 REMICHE, Bernard. Revolução Tecnológica, Globalização e Direito das Patentes. In: VARELLA, Marcelo Dias (Org.). Propriedade Intelectual e Desenvolvimento. São Paulo: Aduaneiras, 2005. p.77.
} 
desenvolvimento de novas drogas. Apesar disso, ao se aprofundar a análise constata-se, por exemplo, que grande parte do financiamento desses investimentos é pública ${ }^{3}$.

Além do mais, questiona-se o fato de que tal proteção seja mesmo mais estimulante ao desenvolvimento da pesquisa científica e das inovações do que o regime de liberdade de informação. $\mathrm{O}$ acesso livre ao conhecimento produzido permitiria a continuidade incessante das pesquisas e ulteriores desenvolvimentos. Este também seria o regime mais interessante para a evolução científica dos países em desenvolvimento. A capacidade científica inovativa não se desenvolve subitamente, são necessários a criação de uma estrutura adequada, a qualificação do pessoal, etc. Nesse sentido, a possibilidade de trabalhar na evolução de produtos já criados constituiria uma fase de transição importante neste processo ${ }^{4}$. Na vigência das atuais regras do TRIPS, no entanto, tal possibilidade é negada a estes países, e o resultado disto é a perpetuação da super concentração da capacidade científica inovativa em pouquíssimos países do globo $^{5}$. Estes mesmos países, no início do desenvolvimento de suas indústrias farmacêuticas, permitiam tranquilamente a cópia de medicamentos, pois consideravam tal prática essencial para o desenvolvimento das mesmas.

No momento atual, com as capacidades produtivas já desenvolvidas, o interesse é diverso, ou seja, evitar que outros países, usando a mesma lógica, possam desenvolver as suas próprias indústrias farmacêuticas, diminuindo o lucro das pioneiras. Ora, poderia o tratamento da questão ser mais privatista? A preocupação toda gira em torno do maior ou do menor lucro, da existência ou da aniquilação da concorrência. Pode-se mesmo aceitar tamanha apropriação do saber? Mais, se o objeto desse conhecimento é um bem essencial à vida, como são os medicamentos, tal tratamento privatista não se apresenta de modo ainda mais revoltante? Pode a questão do maior ou menor acesso da população a este bem essencial não determinar em modo algum o tratamento dado a questão? Essa é a realidade atual.

A perversidade deste regime fica ainda mais evidente quando se analisam os tipos de privilégios que ele atribui aos titulares de patentes. Estes não são simplesmente remunerados pelas suas invenções, mas possuem o direito de exclusividade sobre elas. $\mathrm{Na}$ prática, isto significa que somente eles podem produzir ou autorizar que alguém produza um determinado medicamento, o que, em uma leitura invertida, significa dizer que eles possuem o direito de impedir que outros produzam o bem objeto da proteção.

\footnotetext{
${ }^{3}$ SACHS, Jeffrey. O Divisor Global da Inovação. In: VARELLA, Marcelo Dias (Org.). Propriedade Intelectual e Desenvolvimento. São Paulo: Aduaneiras, 2005. p. 25. 
Este quadro foi ainda mais agravado pelo TRIPS. Com a não-exigência de exploração local para a obtenção de patentes, é possível que, em um determinado país, um medicamento essencial para a população não seja produzido, que as importações não sejam suficientes, e, mesmo assim, seja proibida a sua produção por outra indústria.

Segundo Bernard Remiche, é compreensível que o titular de uma patente em diversos países não tenha condições de explorá-la em todos eles. A questão que se coloca, segundo o autor, é se nestes países onde não a explora, deveria ser mantido o direito de exclusividade na importação e na comercialização e, em que esse privilégio se basearia? Na reciprocidade? Ora, isso seria um engodo para os países subdesenvolvidos e em desenvolvimento, em um mundo caracterizado por tão graves disparidades tecnológicas e científicas ${ }^{6}$.

Diante de todas estas constatações e da pressão humanista que inevitavelmente se desenvolveu, decidiu-se dar um tratamento diferenciado aos medicamentos. Isto ocorreu através da edição da Declaração de Doha sobre o TRIPS e a Saúde Pública, em $2001^{7}$.

\subsection{A exceção legitimadora}

Na Declaração de Doha de 2001, reafirma-se o postulado segundo o qual a proteção da propriedade intelectual contribui para o desenvolvimento de novos medicamentos, mas não se ignora os efeitos que tais garantias possam produzir sobre os preços destes (parágrafo 3).

Afirma-se ainda, sem maiores preocupações práticas, que o TRIPS não impede nem deveria impedir que os Estados-membros implementem medidas de proteção à saúde pública. Seguindo esta premissa então, dispõe que o TRIPS seja sempre interpretado de modo a permitir que os membros possam proteger a saúde pública de suas populações e promover o acesso de todos aos medicamentos (parágrafo 4).

$\mathrm{Na}$ prática, o texto repete a exceção da licença obrigatória (parágrafo $5, \mathrm{~b}$ ) já prevista no acordo TRIPS, e afirma o direito dos países a utilizá-la. Após assegurar aos membros a liberdade de avaliação dos motivos que fundamentam o recurso a uma licença obrigatória, acena que as epidemias de AIDS, tuberculose e malária podem configurar casos de extrema urgência, os quais justificariam o uso da mesma (parágrafo

\footnotetext{
${ }_{7}^{6}$ REMICHE, Bernard, op.cit., p. 118.

Declaração sobre o TRIPS e a Saúde Pública. Adotada em 14 de novembro de 2001. Disponível em: <http://www.wto.org/english/thewto_e/minist_e/min01_e/mindecl_e.htm>. Acesso em 15 jul. 2007.
} 
5, c). A reafirmação de tal direito talvez tenha sido necessária devido ao pouco recurso que se faz a esta flexibilização, como se verá.

Além disto, a declaração prevê a prorrogação até 2016 do prazo durante o qual os países considerados menos avançados não precisam reconhecer patentes aos produtos farmacêuticos (parágrafo 7). E por fim, reconhece a dificuldade que muitos países menos desenvolvidos possam vir a ter na aplicação das licenças obrigatórias por não possuírem uma indústria farmacêutica minimamente desenvolvida, e se compromete a encontrar uma solução para tal problema (parágrafo 6). Este assunto foi então objeto da decisão de 30 de agosto de $2003^{8}$ segundo a qual é facilitada a importação pelos países mais pobres de produtos genéricos mais baratos no âmbito das licenças obrigatórias, caso não tenham capacidade de fabricar eles mesmos tais medicamentos.

Com estas disposições o TRIPS ficou consideravelmente mais simpático. De fato, a exceção da licença obrigatória, apesar de pouco efetiva, e a Declaração de Doha de 2001, apesar de fundamentalmente retórica, contribuíram para que as críticas diminuíssem e para que o TRIPS fosse legitimado como um acordo que contempla não somente o comércio internacional mas que, ao mesmo tempo, possui preocupações humanistas.

É o que afirmam, por exemplo, Robert D. Anderson e Hannu Wager para quem o papel da OMC e dos seus tratados não compromete a proteção dos direitos humanos. Segundo estes autores, as regras e procedimentos criados para o comércio internacional reforçam diretamente os direitos civis ao promover a liberdade de participação nos mercados e a liberdade com relação procedimentos governamentais arbitrários ${ }^{9}$.

Além disso, o sistema de livre comércio contribuiria para o desenvolvimento e a realização dos direitos econômicos, sociais e culturais através do estímulo ao crescimento da economia e da geração dos recursos necessários ao cumprimento destes direitos. No entanto, admitem que o sistema do comércio internacional não sempre opera de modo perfeito e para remediar eventuais problemas, em questões particulares, existem esforços para que se dê um tratamento particular a estas. É o caso, como citam, da questão do acesso aos medicamentos dificultado pela existência de patentes e a edição da Declaração de Doha que pretende emendar o TRIPS com o intuito de facilitar tal acesso em resposta às preocupações de saúde pública ${ }^{10}$.

\footnotetext{
${ }^{8}$ Decisão do Conselho Geral do TRIPS de 30 de agosto de 2003 sobre a implementação do parágrafo 6 da Declaração de Doha sobre o TRIPS e a Saúde Pública. Disponível em: <http://www.wto.org/english/tratop_e/trips_e/implem_para6_e.htm> Acesso em 15 jul. 2007.

9 ANDERSON, Robert D. e WA GER, Hannu. Human rights, development, and the WTO: the cases of intellectual property and competition policy. In: Journal of International Economic Law. Volume 9, number 3, September 2006. p.707.

${ }^{10}$ Ibid., p.709.
} 


\section{O DIREITO À SAÚDE E A INTERNACIONALIZAÇÃO DO DIREITO}

O Direito no cenário mundial atual se internacionaliza, apresentando-se como um sistema interativo, complexo e fortemente instável: diversas e cada vez mais numerosas são as ordens jurídicas e as jurisdições no mundo, de vários níveis e com competências setoriais específicas, o que não parece acompanhar-se de um ganho de eficácia, ao contrário (2.2). Não se trata, no entanto, de um derrota do direito, mas de uma mutação na própria concepção de ordenamento jurídico. A idéia é a de uma necessária reflexão ética, fundada em valores comuns, que possam constituir uma resposta à globalização econômica (2.1).

\subsection{Que humanização é essa? O tímido recurso às licenças obrigatórias.}

É questão imperativa saber até que ponto a propalada preocupação com aspectos humanistas seja efetiva ou apenas retórica. As flexibilizações tão fortemente publicizadas como meios através dos quais a busca absoluta pelo livre comércio se humaniza, na verdade, são muito pouco ou em nada utilizadas. A razão disto pode ser explicada por vários fatores.

O primeiro e mais determinante dentre eles, talvez seja o extremamente forte lobby das indústrias farmacêuticas no mundo. As formas de pressão para impor os próprios interesse são múltiplas, apoio financeiro a políticos, ameaça de retirada de estabelecimentos industriais de determinado país, com consequentes reflexos em questões sociais, etc.

Marcia Angell, membro do Departamento de Medicina Social da Universidade de Harvard e ex-editora chefe do New England Journal of Medicine, afirma que as indústrias farmacêuticas dos Estados Unidos (EUA) investem pesadas cifras anuais em ações que visam a adoção de leis favoráveis ao sistema de liberdade de preços e ao sistema de patentes ${ }^{11}$. As ações se desenvolvem tanto nos EUA quanto em países em desenvolvimento. O peso desta indústria é tamanho que determina a postura a ser adotada pelo governo americano.

Tal fenômeno ocorreu quando da adoção do TRIPS e teve continuidade nas pressões atuais para a não-utilização das licenças obrigatórias. Ilustram bem esse fato, as pressões e críticas expressas à recente licença obrigatória implementada pelo Brasil

${ }^{11}$ ANGELL, Márcia. A verdade sobre os laboratórios farmacêuticos: como somos enganados e o que podemos fazer a respeito. Rio de Janeiro: Record, 2007. 
para o medicamento Efavirenz produzido pela americana Merck completamente em desacordo com o texto da Declaração de Doha. Como se viu, este texto reafirma o direito dos países membros da OMC a fazer uso das flexibilizações previstas no TRIPS. No entanto, o que a realidade parece deixar claro é que tais exceções foram pensadas e criadas de modo a não se efetivarem.

Segundo Bernard Remiche, um panorama sumário da evolução do sistema de patentes mostra uma ampliação da proteção, uma consolidação dos direitos e um enfraquecimento das exigências. Tratando especificamente destas últimas, ele relembra que uma das principais exigências para o registro das patentes é a clara, completa e suficiente descrição da invenção, no sentido de que um profissional, com bases nestas informações, seja capaz de implementar o produto.

Por conseguinte, a maior e mais rápida difusão dos conhecimentos que essa exigência proporciona constitui a principal contrapartida do monopólio temporário que são as patentes. No entanto, tal exigência vem sendo negligenciada ao se permitir que o inventor limite cada vez mais a descrição das invenções. Isto contribui, segundo o autor para o fracasso generalizado das licenças obrigatórias.

Assim, sem desconsiderar o avanço obtido com a Declaração de Doha, o balanço passados cinco anos da sua edição aponta para a frustração das expectativas otimistas geradas na época para uma melhora na proteção das populações pobres ${ }^{12}$. Se as flexibilizações do TRIPS não retiram as dificuldades que este impõe à promoção do acesso à saúde, não se pode dizer, portanto, que este acordo se enquadre em um panorama de internacionalização do direito que se guie por valores humanistas, como se deseja.

\subsection{Que internacionalização é essa? A que(m) serve?}

O acordo TRIPS uniformiza e impõe um conteúdo mínimo de proteção aos direitos de propriedade intelectual aos membros da OMC. Com essas características, ele pode ser inserido no fenômeno atual de internacionalização do direito. Esta internacionalização é influenciada por dois principais fatores, contraditórios, a universalização dos direitos humanos e a globalização econômica. A contradição que se coloca entre internacionalização ética e globalização econômica é na verdade, uma

\footnotetext{
${ }^{12}$ PRONER, Carol. Propriedade intelectual: para uma outra ordem jurídica possível. São Paulo: Cortez, 2007. p. 109.
} 
contradição entre a idéia mesma de universalismo que supõe solidariedade e a sociedade de mercado que produz competição e desigualdades ${ }^{13}$.

Segundo Delmas-Marty, a universalização normativa pautada por valores humanistas é a solução hoje existente para melhor enquadrar a globalização. Não é mais possível a defesa do relativismo pois este pressupõe a existência de dois elementos, a total independência de cada país com relação aos outros e a plena autonomia de todos, os quais não estão presentes em uma sociedade global. O risco que se corre, neste caso é o de, ao negar o universalismo e a busca de normas comuns equilibradas, dar lugar a uma espécie de 'relativismo imperialista', no qual existe sim apenas uma regra que se impõe a todos, mas diversamente de uma regra consensualmente construída, essa é a regra do mais forte ${ }^{14}$.

O TRIPS, apesar de ter sido adotado por consenso no âmbito da OMC, não pode ser considerado uma normativa equilibrada, construída para atender interesses diversos e segundo valores humanistas. A realidade é que o TRIPS reflete claramente uma concepção sobre os direitos de propriedade intelectual, a concepção dos países desenvolvidos. $\mathrm{O}$ argumento principal em defesa deste sistema é a infinitamente repetida afirmação de que este favorece a pesquisa científica e o desenvolvimento de novos medicamentos. Argumento que é falso, ao menos, na forma simplista com a qual se impõe. Carlos Correa, em brilhante estudo que analisa o dilema existente no campo da inovação entre conceder incentivos aos inovadores e permitir à sociedade o máximo uso dos produtos inovadores, assim esclarece a questão:

A eficiência exige que se minimize o custo da inovação não apenas para o inovador, mas também para a sociedade. Como se mencionou, os direitos de propriedade intelectual, por sua própria natureza, reduzem a eficiência estática e, em consequência, o bem-estar da sociedade, a fim de teoricamente, gerar eficiência dinâmica ao promover inovação. Entretanto, os direitos de propriedade intelectual não levam, nem automática, nem inevitavelmente, a alcançar esse objetivo. A concessão de direitos exclusivos aumenta a possibilidade de apropriação e pode estimular o investimento em atividades inovadoras, mas reduz a disponibilidade de conhecimento, retardando, com isso, a inovação; a sociedade se beneficia mais se os competidores tiverem a permissão de rapidamente imitar e aperfeiçoar a inovação, a fim de assegurar-lhe a disponibilidade a preços competitivos ${ }^{15}$.

\footnotetext{
${ }^{13}$ ARNAUD, André-Jean. O Direito entre Modernidade e Globalização: lições de Filosofia do Direito e do Estado. Rio de Janeiro: Renovar, 1999. p 201.

${ }^{14}$ DELMAS-MARTY, Mireille. Les forces imaginantes du droit. Le Relatif et l'Universel. Paris: Seuil, 2004. p. 231 - 240.

${ }^{15}$ CORREA, Carlos M.. Aperfeiçoando a Eficiência Económica e a Equidade pela Criação de Leis de Propriedade Intelectual. In: VARELLA, Marcelo Dias (Org.) Propriedade intelectual e desenvolvimento. São Paulo: Ed. Aduaneiras, 2005. p. 45 e 46.
} 
Além do mais, segundo o mesmo autor, a questão do equilíbrio entre os interesses conflitantes das indústrias farmacêuticas que produzem inovações e da sociedade que pretende desfrutar da forma mais ampla e rápida de tais produtos deve ser analisada diferentemente segundo as diferentes regiões do mundo e seus níveis de desenvolvimento econômico.

De fato, uma forte proteção aos direitos de propriedade intelectual nos países em desenvolvimento dificulta gravemente o acesso aos novos bens sem contribuir ao desenvolvimento tecnológico destes países, ao contrário, contribuindo para a perpetuação da dependência tecnológica dos países do Sul para com os países do Norte $^{16}$.

Enfim, a internacionalização do direito está em curso. No âmbito das regras comerciais a OMC é inegavelmente um sucesso. O livre comércio predomina na escala de valores e alguns tentam provar que os objetivos deste não impedem a efetivação do direito à saúde, ao contrário a promovem. Os fatos falam diversamente. Vejam-se os dados apresentados no âmbito do Projeto do Milênio, constituído pelo Secretário-Geral da Nações Unidas em 2002: todos os dias o vírus da AIDS é responsável pela morte de 6000 pessoas, e nas mesmas 24h, outras 8200 são infectadas. A cada 30 segundos, uma criança africana morre devido à malária - o que significa mais de um milhão de crianças mortas por ano. A cada ano, aproximadamente 300 a 500 milhões de pessoas são infectadas pela malária. Cerca de três milhões de pessoas morrem por causa da doença. Tuberculose é a principal causa de morte relacionada com a AIDS e, em algumas partes da África, $75 \%$ das pessoas portadoras do vírus HIV também têm tuberculose ${ }^{17}$.

Desafortunadamente, portanto, o impacto do acordo TRIPS sobre o direito à saúde mostra-se enormemente negativo. Numa perspectiva humanista - aliás, a única possível para o direito, impõe-se a urgente revisão do marco regulatório internacional sobre o saber que permite a cura ou a minimização do sofrimento de milhões de seres humanos.

\section{REFERÊNCIAS BIBLIOGRÁFICAS}

\footnotetext{
${ }^{16}$ VARELLA, Marcelo Dias. Direito Internacional Econômico Ambiental. Belo Horizonte: Del Rey, 2004. p. 185.

${ }^{17}$ Projeto do Milênio. Números da crise. Disponível em: 〈http://www.pnud.org.br/milenio/numeroscrise.php〉 Acesso em 15 jul. 2007.
} 
ANDERSON, Robert D. e WAGER, Hannu. Human rights, development, and the WTO: the cases of intellectual property and competition policy. In: Journal of International Economic Law. Volume 9, number 3, September 2006.

ANGELL, Marcia. A verdade sobre os laboratórios farmacêuticos: como somos enganados e o que podemos fazer a respeito. Rio de Janeiro: Record, 2007.

CORREA, Carlos M.. Propriedade Intelectual e Saúde Pública. Florianópolis: Boiteux, 2007.

CORREA, Carlos M.. Aperfeiçoando a Eficiência Económica e a Equidade pela Criação de Leis de 